\title{
NKG2D and DNAM-1 activating receptors and their ligands in NK-T cell interactions: role in the NK cell-mediated negative regulation of $\mathrm{T}$ cell responses
}

\author{
Alessandra Zingoni ${ }^{1}{ }^{*}$, Michele Ardolino $^{1+}{ }^{\dagger}$, Angela Santoni $^{1,2}$ and Cristina Cerboni ${ }^{1}$ \\ 'Department of Molecular Medicine, Istituto Pasteur-Fondazione Cenci Bolognetti, "Sapienza" University of Rome, Rome, Italy \\ ${ }^{2}$ Neuromed, Pozzilli, Italy
}

\section{Edited by:}

Eric Vivier, Centre d'Immunologie de Marseille-Luminy, France

\section{Reviewed by:}

Georges Leclercq, Ghent University, Belgium

Jacques Zimmer, Centre de Recherche Public de la Santé, Luxembourg

\section{*Correspondence:}

Alessandra Zingoni, Department of Molecular Medicine, Istituto Pasteur-Fondazione Cenci Bolognetti, "Sapienza" University of Rome, Viale Regina Elena 291, 00161 Rome, Italy. e-mail: alessandra.zingoni@ uniroma1.it

${ }^{\dagger}$ Present address:

Michele Ardolino, Department of Molecular and Cell Biology, University of California at Berkeley, Berkeley, CA 94720-3200, USA.
The negative regulation of adaptive immunity is relevant to maintain lymphocyte homeostasis. Several studies on natural killer (NK) cells have shown a previously unappreciated immunomodulatory role, as they can negatively regulate $T$ cell-mediated immune responses by direct killing and by secretion of inhibitory cytokines. The molecular mechanisms of T cell suppression by NK cells, however, remained elusive. Only in the last few years has it become evident that, upon activation, human T cells express MICA-B, ULBP13 , and PVR, ligands of the activating receptors NKG2D and DNAM-1, respectively. Their expression renders $T$ cells targets of NK cell lysis, representing a new mechanism taking part to the negative regulation of $T$ cell responses. Studies on the expression of NKG2D and DNAM-1 ligands on T cells have also contributed in understanding that the activation of ATM (ataxia-telangiectasia, mutated)/ATR (ATM/Rad3-related) kinases and the DNA damage response is a common pathway regulating the expression of activating ligands in different types of cells and under different conditions. The functional consequences of NKG2D and DNAM-1 ligand expression on activated T cells are discussed in the context of physiologic and pathologic processes such as infections, autoimmunity, and graft versus host disease.

Keywords: NKG2D ligands, DNAM-1 ligands, NK-T cell cross-talk, DNA damage response, cell proliferation
Natural killer (NK) cells contribute to the suppression of T cell responses and to the maintenance of $\mathrm{T}$ lymphocyte homeostasis through the release of inhibitory cytokines, such as TGF- $\beta$ and IL-10, which can inhibit dendritic cell (DC) maturation or T cell activation and functions, and/or through the direct elimination of antigen-presenting cells and activated T cells (Andoniu et al., 2008). The activating receptors expressed by NK cells and involved in the direct elimination of $\mathrm{T}$ cells remain still elusive although they have been recently focus of intense research. 2B4/CD244, LFA-1/CD11a/CD18, NKp46/CD335, NKp30/CD337, KIR2DS1/CD158h, and in particular NKG2D/CD314 and DNAM-1/CD226 appear to play a prominent role.

\section{EXPRESSION OF NKG2D AND DNAM-1 LIGANDS ON T CELLS NKG2D AND ITS LIGANDS}

NKG2D is an activating receptor expressed on NK cells, CD8 ${ }^{+} \mathrm{T}$ cells and $\gamma / \delta \mathrm{T}$ cells that binds to several inducible self-proteins belonging to the MIC (MICA, MICB) and ULBP (ULBP1 to ULBP6) families in humans, and H60 (a-c), Rae $(\alpha-\varepsilon)$ and MULT1 in mice (Eagle and Trowsdale, 2007). NKG2D ligands (NKG2DLs) are mainly induced on the surface of transformed, infected or otherwise "stressed" cells, while the expression on healthy cells is low. However, increasing evidences show that NKG2DLs can be constitutively expressed or induced on normal hematopoietic cells including bone marrow cells (Nowbakht et al., 2005; Poggi et al., 2005; Spaggiari et al., 2006), mature DCs (Jinushi et al., 2003a,b;
Andoniou et al., 2005; Schrama et al., 2006; Galazka et al., 2007; Qiao et al., 2008), monocytes and macrophages (Hamerman et al., 2004; Nowbakht et al., 2005; Nedvetzki et al., 2007; Kloss et al., 2008; Schulz et al., 2010), B cells (Nowbakht et al., 2005), and $\mathrm{T}$ cells. In general, NKG2DLs are not expressed by resting $\mathrm{T}$ lymphocytes, but their expression can be induced by different stimuli (Table 1). The first evidence of NKG2DL expression on $\mathrm{T}$ cells came from a study by Molinero et al. (2002) indicating that human T cells can express MICA in response to alloantigen and to CD3/CD28 cross-linking. Furthermore, also other NKG2DLs namely MICA, MICB, and ULBP1-3, but not ULBP4, are detected on both $\mathrm{CD}^{+}$and $\mathrm{CD}^{+} \mathrm{T}$ lymphocytes following stimulation with alloantigens, SEB superantigen, a specific antigenic peptide or upon PMA/ionomycin treatment (Cerboni et al., 2007a, 2009). As a consequence, activated $\mathrm{T}$ cells become susceptible to autologous NK cell lysis, with an NKG2D/NKG2DL-dependent mechanism (Cerboni et al., 2007a). Nielsen et al. (2012) further demonstrated that NKG2D, LFA-1, and NKp46 are involved in NK cell degranulation triggered by activated autologous $\mathrm{CD} 4^{+} \mathrm{T}$ cells, with both subsets of human NK cells (CD56 ${ }^{\mathrm{dim}}$ and CD56 $6^{\text {bright }}$ ) equally cytotoxic. Expression of NKG2DLs was described also on regulatory T cells (Treg) in response to Mycobacterium tuberculosis and NKcell mediated lysis of Treg involves both NKG2D and NKp46 (Roy et al., 2008). Expression of NKG2DLs was also reported on activated murine T cells. H60 is up-regulated on T cells upon in vitro stimulation with ovalbumin and $\mathrm{T}$ cell blasts become susceptible 
Table 1 | Different stimuli implicated in the induction or up-regulation of NKG2D and DNAM-1 ligands on activated T cells.

\begin{tabular}{|c|c|c|c|c|c|}
\hline & Stimulus & NKG2DLs & DNAM1Ls & T cell type & Reference \\
\hline \multirow[t]{15}{*}{ Human } & anti-CD3 plus anti-CD28 & MICA/B & PVR & T cells & Molinero etal. (2002), \\
\hline & & ULBP1-3 & & & Nielsen et al. (2012) \\
\hline & Superantigen, alloantigen, PMA/ & MICA/B, & & $\mathrm{CD}^{+}$and & Cerboni etal. (2007a), \\
\hline & ionomycine, antigenic peptide & ULBP1-3 & & $\mathrm{CD}^{+} \mathrm{T}$ cells & Cerboni et al. (2009) \\
\hline & Anti-CD3 plus IL-2 & MICA & & $\mathrm{CD}^{+} \mathrm{T}$ cells & Maasho et al. (2005) \\
\hline & Superantigen & & PVR, Nectin-2 & T cells & Ardolino et al. (2011) \\
\hline & PHA & & PVR & $\mathrm{CD}^{+}{ }^{+} \mathrm{T}$ cells & Cella et al. (2010) \\
\hline & Histone deacetylase inhibitors & MICA/B & & Jurkat and activated & Skov et al. (2005) \\
\hline & & & & $\mathrm{T}$ cells & \\
\hline & Propionic acid & MICA/B & & Jurkat and activated & Andresen et al. (2009) \\
\hline & & & & $\mathrm{CD}^{+}{ }^{+} \mathrm{T}$ cells & \\
\hline & M. tuberculosis & ULBP-1 & & Treg & Roy et al. (2008) \\
\hline & HIV & MICA, & & Jurkat and activated & Cerboni etal. (2007b), \\
\hline & & ULBP-1, 2,3 & & $\mathrm{CD}^{+}{ }^{+} \mathrm{T}$ cells & Ward et al. (2007) \\
\hline & HIV & & PVR & Activated $\mathrm{CD} 4^{+} \mathrm{T}$ cells & Matusali et al. (2012) \\
\hline \multirow[t]{2}{*}{ Mouse } & $\mathrm{mHA}$ antigen & H60, MULT1 & & $\mathrm{CD}^{+}{ }^{+} \mathrm{T}$ cells & Noval Rivas etal. (2010) \\
\hline & ConA, PMA/ionomycine, ovalbumin & H60 & & T cells & Rabinovich et al. (2003) \\
\hline
\end{tabular}

to syngeneic NK cell killing (Rabinovich et al., 2003). Of note, an in vivo study showed that chronic antigenic stimulation of $\mathrm{CD} 4^{+}$ T lymphocytes determined up-regulation of H60 and MULT1 ligands (Noval Rivas et al., 2010). NKG2DL expression was observed on thymocytes of BALB/c mice and was modulated during thymocyte development, suggesting a possible but yet undefined function in this process (Li et al., 2005). In support of these findings, a role for NK cell-mediated cytotoxicity during thymocyte development was demonstrated (Schott et al., 2003).

\section{DNAM-1 AND ITS LIGANDS}

DNAM-1/CD226 is an activating receptor belonging to the Ig superfamily and is constitutively expressed by most NK cells, T cells, macrophages, and DCs. DNAM-1 interacts with LFA-1, required for its functional activity on both $\mathrm{NK}$ and cytotoxic $\mathrm{T}$ cells (Shibuya et al., 1996). Ligands for DNAM-1 (DNAM1Ls) include Nectin-2/CD112 and PVR/CD155 belonging to the Nectin/Nectin-like family of adhesion molecules (Bottino et al., 2003; Tahara-Hanaoka etal., 2004). The activating effects of DNAM-1 can be counteracted by TIGIT, a recently identified inhibitory receptor binding to PVR, and expressed by T and NK cells (Stanietsky et al., 2009). DNAM1Ls are broadly distributed on hematopoietic, epithelial, and endothelial cells as well as on several tumors (Bottino et al., 2003; Pende et al., 2006; Tahara-Hanaoka et al., 2006). We have shown that PVR and Nectin-2 are induced on $\mathrm{T}$ cells in response to SEB stimulation at both the mRNA and protein levels, but only PVR can reach the cell surface (Ardolino et al., 2011). PVR expression on $\mathrm{CD}^{+} \mathrm{T}$ lymphocytes was also observed upon phytohemagglutinin (PHA) stimulation or coengagement of CD3/CD28 molecules (Cella et al., 2010; Nielsen et al., 2012; Table 1). DNAM-1/PVR axis is involved in the NK cell-mediated lysis of allogeneic activated T cells (Ardolino et al., 2011), while in an autologous setting, NKG2D emerges as the dominant receptor (Rabinovich et al., 2003; Cerboni et al., 2007a; Nielsen et al., 2012).

\section{ROLE OF THE DDR IN THE REGULATION OF NKG2D AND DNAM-1 LIGANDS ON ACTIVATED T LYMPHOCYTES}

NKG2DL expression is tightly regulated at various levels. During malignant transformation, cells undergo genotoxic or other forms of cellular stress with de novo expression of NKG2DLs. Gasser et al. (2005) demonstrated that murine and human NKG2DLs are up-regulated in fibroblasts by genotoxic stress and stalled DNA replication, conditions known to activate the DNA damage response (DDR) initiated by ATM (ataxia-telangiectasia, mutated) or ATR (ATM/Rad3-related) kinases. Studies aimed at investigating the signaling pathways leading to NKG2DL expression on antigen-activated T cells highlighted a role for the DDR as well. Treatment with ATM/ATR inhibitors blocked MICA induction on $\mathrm{T}$ cells with a mechanism involving NF- $\kappa \mathrm{B}$ (Cerboni et al., 2007a), which regulates MICA expression on activated T lymphocytes by binding a specific sequence in the long intron 1 of the MICA gene (Molinero et al., 2004). NKG2DLs were found also on HIV-infected $\mathrm{CD} 4^{+} \mathrm{T}$ cells and their expression requires the activation of the DDR and stress pathways, via the HIV-1encoded molecule Vpr (Ward et al., 2009; Richard et al., 2010; Pham et al., 2011), a potent activator of ATR and of a cell cycle arrest in $\mathrm{G}_{2}$ (He et al., 1995; Jowett et al., 1995; Re et al., 1995; Roshal et al., 2003). Similarly, oxidative stress and DDR strongly contribute to induce PVR expression on activated T cells (Ardolino et al., 2011). Thus, activation of ATM/ATR kinases and DDR could be a common pathway regulating the expression of different 
activating ligands on $\mathrm{T}$ lymphocytes. Of note, we also found that genotoxic stress triggered ATM/ATR-dependent up-regulation of both DNAM1Ls and NKG2DLs on multiple myeloma cells (Soriani et al., 2009).

Increasing evidences show the involvement of DDR in many physiological processes, such as mitosis (Oricchio et al., 2006), insulin response (Yang and Kastan, 2000), V(D)J recombination (Chen et al., 2000) or after lipopolysaccharide stimulation in macrophages (Eissmann et al., 2010). In addition, up-regulation of ATM protein levels was observed in PBMCs (peripheral blood mononuclear cells) in response to mitogenic stimuli (Fukao et al., 1999). Increased phosphorylation of either ATM or one of its substrates, the histone H2AX, was described on T cells upon CD3 triggering, PHA or SEB stimulation (Cerboni et al., 2007a; Tanaka et al., 2007; Ardolino et al., 2011). Remarkably, PVR and NKG2DLs expression was mainly observed on T cells that had gone through at least one mitosis (Cerboni et al., 2007a, 2009; Ardolino et al., 2011). This is only one of the numerous examples showing a correlation of either NKG2DL or PVR expression with cell proliferation. In murine bone marrow grafts, Rae-1 was detected on donor proliferating hematopoietic cells in the spleen of the transplant recipients rather than on the long-term hematopoietic stem cells (Ogasawara et al., 2005). The presence of MIC molecules on rheumatoid arthritis synoviocytes was strongly associated with the expression of the nuclear Ki-67 proliferation marker (Groh et al., 2003) and MIC gene promoter contains elements for cell proliferation-associated transcriptional activation (Venkataraman et al., 2007). A preferential expression of PVR on proliferating rat hepatocytes during liver regeneration and acute injury was previously described (Erickson et al., 2006). These authors also reported that PVR expression in epithelial cells was tightly regulated by changes in cell density. NK cells react more efficiently to concanavalin A-stimulated, proliferating MHC class I-deficient target cells than to non-activated cells in vitro and in vivo (Correa et al., 1994) and proliferating T cells become more susceptible to NK cell killing (Ardolino et al., 2011). In line with these results, Davis's group reported that human NK cells bound to cells in mitosis more effectively than the same cells in other phases of the cell cycle (Nolte-'t Hoen et al., 2007). Thus, we envisage that the expression of PVR and NKG2DLs on proliferating T lymphocytes is a possible mechanism used by NK cells to restrict the expansion of activated/proliferating T cells (Figure 1).

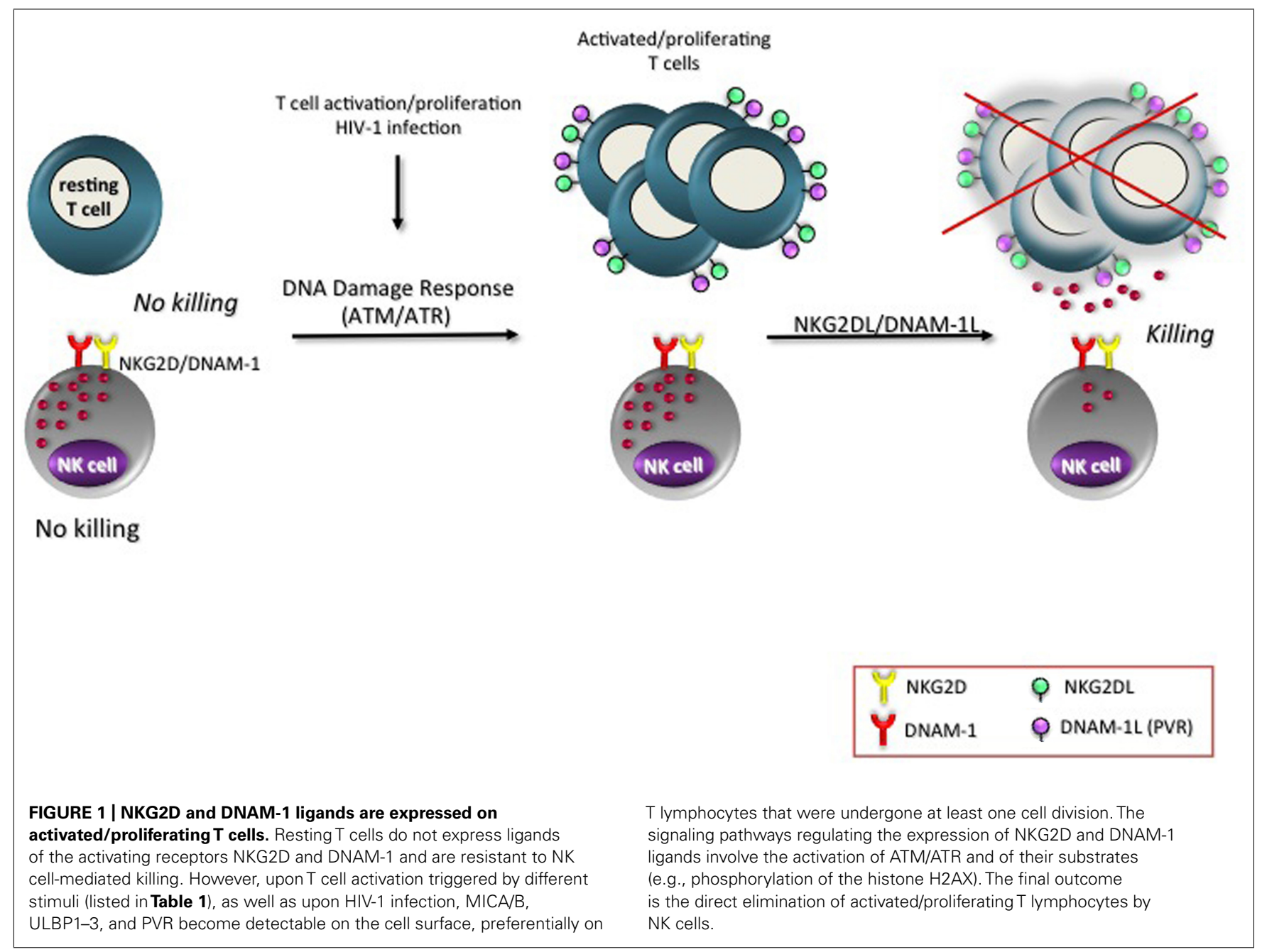




\section{IN VIVO RELEVANCE FOR NK-T CELL INTERACTION VIRAL INFECTIONS}

A plethora of studies analyzed the role of NKG2D/NKG2DL axis by looking at infected cells, which very often express one or more ligands. These studies have demonstrated that NKG2D plays an important role in anti-viral immunity, via a direct NK cell-mediated lysis of infected cells. This evidence is also underscored by the countermeasures taken by viruses to avoid NKG2D-mediated triggering (Lanier, 2008; Rossini et al., 2012). However, NK cell contribution to anti-viral immunity can be seen also from another point of view: NK cells might restrain anti-viral $\mathrm{T}$ cell responses, thus promoting the return to $\mathrm{T}$ cell homeostasis.

In vivo depletion studies established that $\mathrm{NK}$ cells act to negatively regulate $\mathrm{CD}^{+}{ }^{+}$and $\mathrm{CD}^{+}{ }^{+} \mathrm{T}$ cell-dependent IFN- $\gamma$ production and proliferation during murine cytomegalovirus infection, and they can mediate a similar effect on $\mathrm{CD} 4^{+} \mathrm{T}$ cell responses during lymphocytic choriomeningitis virus (LCMV) infection in $\beta 2$-microglobulin deficient mice ( $\mathrm{Su}$ et al., 2001). Accordingly, a more recent study showed that perforin-deficient mice chronically infected with LCMV contain greater numbers of activated anti-viral $\mathrm{T}$ cells compared to control animals. The accumulation of activated $\mathrm{CD} 8^{+} \mathrm{T}$ cells resulted in mortality within 2-4 weeks, an event which is rarely seen following an i.p. injection with LCMV of normal mice (Matloubian et al., 1999). It was described also a three-way of NK-T cell interaction, where NK cells directly eliminate activated $\mathrm{CD}^{+}{ }^{+} \mathrm{T}$ cells (via a perforindependent pathway), thereby affecting $\mathrm{CD} 8^{+} \mathrm{T}$ cell function with beneficial or detrimental effects depending on the viral dose. However, no role for NKG2D/NKG2DLs could be observed (Waggoner et al., 2011). In another study, NK cell depletion promoted LCMVinduced $\mathrm{CD}^{+} \mathrm{T}$ cell immunity with the involvement of both perforin and NKG2D (Lang et al., 2012). Altogether, these studies show that NK cells can be crucial in controlling viral infections not only by a direct elimination of infected cells, but also by altering the number and functions of virus-specific T cells. However, the role of NKG2D and other activating receptors awaits a better elucidation.

Considering HIV-1, a virus replicating (among other cell types) in $\mathrm{CD}^{+}{ }^{+} \mathrm{T}$ lymphocytes, we face a situation where NK cell targeting of activated $\mathrm{T}$ cells via NKG2D means, at the same time, eliminating the infected cell. In fact, expression of several NKG2DLs was observed on HIV-1 infected CD4 ${ }^{+} \mathrm{T}$ cells, with increased susceptibility to NK lysis (Cerboni et al., 2007b; Ward et al., 2007; Fogli et al., 2008; Richard et al., 2010). However, HIV-1 has also evolved its own countermeasures as it can also down-regulate NKG2DLs via Nef and Vif proteins (Cerboni et al., 2007b; Norman et al., 2011). Thus, regulation of NKG2DL expression by Vpr, Nef and possibly other viral proteins might have different impacts on $\mathrm{NK}$ cell recognition of infected $\mathrm{CD} 4^{+}$ T cells.

The role of DNAM-1 and its ligands in the context of NK-T cell interactions during viral infections has been less investigated. Recently, PVR was detected on HIV-1 infected CD4 ${ }^{+} \mathrm{T}$ cells, and when the NKG2D pathway was inhibited, additional blocking of DNAM-1 strongly impaired the capacity of NK cells to kill HIV-1-infected cells, indicating the involvement of both receptors (Matusali et al., 2012). However, expression of PVR on
$\mathrm{CD}^{+}{ }^{+} \mathrm{T}$ cells might also be responsible for the down-regulation of DNAM-1 on CD8 ${ }^{+}$T cells observed in chronic HIV-1 infection (Cella et al., 2010).

\section{AUTOIMMUNITY}

The mechanisms by which NK cells modulate adaptive immune responses in the course of autoimmune diseases have been addressed by a large number of in vivo and in vitro studies. However, depending on the model system, NK cells might either promote or inhibit the generation and proliferation of autoreactive T cells (French and Yokoyama, 2004; Shi and Van Kaer, 2006; Flodström-Tullberg et al., 2009; Lünemann et al., 2009).

Thinking in terms of negative regulation of (autoreactive) $\mathrm{T}$ cell responses, NK cells might exert a direct effect on activated, autoantigen-specific $\mathrm{T}$ cells. In experimental autoimmune encephalomyelitis (EAE), in vivo depletion of NK cells exacerbated demyelination and the clinical features of EAE; in addition, in vitro studies have shown that direct NK-T cell contact inhibited T cell proliferation and cytokine production triggered by myelin-derived peptides (Zhang et al., 1997; Matsumoto et al., 1998; Smeltz et al., 1999; Xu et al., 2005). NK cells might thus ameliorate the course of EAE by limiting the expansion of myelin-reactive $\mathrm{T}$ cells in the periphery and in the absence of their suppressive action, central nervous system inflammation became more marked. However, these studies are in conflict with another report showing that NK cell depletion resulted in less severe clinical scores (Shi et al., 2000). In an in vivo model of colitis, NK cell-depleted animals developed accelerated disease, and it was suggested that NK cells inhibited effector $\mathrm{CD}_{4}{ }^{+} \mathrm{T}$ cells in a perforin-dependent manner (Fort et al., 1998; Yamaji et al., 2012). Such a protective effect also occurred in Staphylococcus aureus- and collagen-induced arthritis (CIA; Nilsson et al., 1999; Leavenworth et al., 2011), as well as in NOD mice (Lee et al., 2004).

A number of studies have identified the cytolytic mechanism underlying NK cell-mediated killing of autoreactive T cells, and the NK cell-mediated immunoregulatory activity was shown to be perforin-dependent in animal models of colitis, EAE, and CIA (Fort et al., 1998; Lu et al., 2007; Leavenworth et al., 2011). Thus, the receptor/ligand interactions triggering a perforin-mediated cytotoxicity play a key role in controlling $\mathrm{T}$ cell responses, and NKG2D might be part of the picture, since it plays a major role in NK cell lysis of autologous activated T cells (Rabinovich et al., 2003; Cerboni et al., 2007a; Nielsen et al., 2012). Moreover, NK cells can lyse autologous DCs, that under certain circumstances - including EAE - express NKG2DLs (Jinushi et al., 2003a,b; Andoniou et al., 2005; Schrama et al., 2006; Galazka et al., 2007; Qiao etal., 2008). These data, together with NKG2DL expression also on activated macrophages and monocytes, bone marrow cells and microglia (Lünemann etal., 2008), indicate that this receptor/ligand pair might play a more general immunoregulatory role besides killing autoreactive $\mathrm{T}$ cells, e.g., by eliminating macrophages and other antigen-presenting cells or their precursors under inflammatory conditions, as a feedback mechanism to silence uncontrolled antigen-specific immune responses.

The role of NKG2D/NKG2DLs in autoimmunity has been addressed also from another point of view. In fact, endogenous cells and/or tissues can aberrantly express NKG2DLs (as shown in 
particular for MICA and MICB in humans and Rae-1 in mice), promoting activation of autoreactive infiltrating $\mathrm{NKG}_{2} \mathrm{D}^{+} \mathrm{T}$ cells, leading to tissue destruction. Examples of this condition can be found in human type I diabetes and in NOD mice, in patients with rheumatoid arthritis, Crohn's disease, celiac disease, and in a mouse model of autoimmune vitiligo. These aspects are however reviewed elsewhere (Shi and Van Kaer, 2006; Van Belle and von Herrath, 2009).

Regarding DNAM-1, despite the expression of PVR on activated T cells (Cella et al., 2010; Ardolino et al., 2011; Nielsen et al., 2012), its role was not evident in autologous NK-T combinations (Ardolino et al., 2011; Nielsen et al., 2012), while it was relevant in allogeneic settings (Ardolino et al., 2011), suggesting that DNAM-1 might not be involved in autoimmune reactions.

\section{GRAFT VERSUS HOST DISEASE}

Allogeneic bone marrow transplantation (BMT) was estimated to be an effective treatment for hematologic malignancies and some solid tumors. However, the high incidence of graft versus host disease (GVHD) mediated by the activation and proliferation of alloreactive $\mathrm{T}$ cells leads to severe host tissue damage. Previous studies demonstrated that donor NK cells are able to suppress the development of GVHD through the killing of host antigen-presenting cells which are essential for donor $\mathrm{T}$ cell activation (Ruggeri et al., 2002). More recently, several in vivo studies in the mouse showed a direct effect of donor NK cells on GVHD-inducing T cells. Allogeneic T cells and NK cells trafficked similarly after BMT (Olson et al., 2009) and donor NK cells limited the expansion of syngeneic donor $\mathrm{T}$ cells through different mechanisms mediated by perforin and Fas-FasL interaction (Olson et al., 2010). Similarly, in a model of chronic GVHD,

\section{REFERENCES}

Andoniou, C. E., van Dommelen, S. L., Voigt, V., Andrews, D. M. Brizard, G., Asselin-Paturel, C., et al. (2005). Interaction between conventional dendritic cells and natural killer cells is integral to the activation of effective antiviral immunity. Nat. Immunol. 10, 1011-1019.

Andoniu, C. E., Coudert, J. D., and Degli Esposti, M. A. (2008). Killers and beyond: NK-cell-mediated control of immune response. Eur. J. Immunol. 38, 2938-2942.

Andresen, L., Hansen, K. A., Jensen, H., Pedersen, S. F., Stougaard, P., Hansen, H. R., et al. (2009). Propionic acid secreted from propionibacteria induces NKG2D ligand expression on human-activated T lymphocytes and cancer cells. J. Immunol. 183, 897-906.

Ardolino, M., Zingoni, A., Cerboni, C., Cecere, F., Soriani, A., Iannitto, M. L., et al. (2011). DNAM-1 ligand expression on Ag-stimulated T lymphocytes is mediated by ROS-dependent activation of DNA-damage response: relevance for NK-T cell interaction. Blood 117, 4778-4786.
Bottino, C., Castriconi, R., Pende, D., Rivera, P., Nanni, M., Carnemolla, B., et al. (2003). Identification of PVR (CD155) and Nectin-2 (CD112) as cell surface ligands for the human DNAM-1 (CD226) activating molecule. J. Exp. Med. 198, 557-567.

Cella, M., Presti, R., Vermi, W., Lavender, K., Turnbull, E., OchsenbauerJambor, C., et al. (2010). Loss of DNAM- 1 contributes to CD8 ${ }^{+}$T-cell exhaustion in chronic HIV-1 infection. Eur. J. Immunol. 40, 949-954.

Cerboni, C., Zingoni, A., Cippitelli, M., Piccoli, M., Frati, L., and Santoni, A. (2007a). Antigen-activated human $\mathrm{T}$ lymphocytes express cell-surface NKG2D ligands via an ATM/ATR dependent mechanism and become susceptible to autologous NK-cell lysis. Blood 110, 606-615.

Cerboni, C., Neri, F., Casartelli, N., Zingoni, A., Cosman, D., Rossi, P., et al. (2007b). Human immunodeficiency virus 1 Nef protein downmodulates the ligands of the activating receptor NKG2D and inhibits natural killer cell-mediated cytotoxicity. $J$. Gen. Virol. 88, 242-250.

donor NK cells could restrain the expansion of antigen-specific $\mathrm{CD}^{+} \mathrm{T}$ cells responsible for GVHD. Interestingly, $\mathrm{T}$ cells under chronic antigenic stimulation up-regulated NKG2DLs and the immunoregulatory activity of NK cells was inhibited by injection of antibodies directed to NKG2D (Noval Rivas et al., 2010). In humans, a fraction of KIR2DS1 ${ }^{+}$NK cells can mediate strong alloreactivity against both $\mathrm{mDC}$ and activated $\mathrm{T}$ lymphocytes and DNAM-1 and NKp30 were shown to be involved in this process, supporting an important role of NK cells in the prevention of GVHD (Sivori et al., 2011).

\section{CONCLUSION}

In summary, a central role for NK cell killing in mediating immunoregulatory effects is emerging. Studies of different conditions (infections, autoimmunity, transplants) indicate that NK cytotoxicity of activated $\mathrm{T}$ cells, as well as of other cells of the immune system, is important in immune regulation. The involvement of NKG2D and DNAM-1 receptors may represent the "tip of the iceberg," with significant effects on the negative regulation of adaptive $\mathrm{T}$ cell responses, resulting in increased viral burdens, viral persistence, and/or inflammation. The locations where these events take place, and which are the NK cell subsets involved are still rather obscure parts of the picture.

\section{ACKNOWLEDGMENTS}

The authors are supported by grants of the Italian Ministry of Health (Giovani Ricercatori n. 000307 to Alessandra Zingoni), the Italian Association for Cancer Research (AIRC), AIRC $5 \times 1000$, and the "Sapienza" University of Rome. Michele Ardolino is a recipient of a fellowship from Istituto Pasteur-Fondazione Cenci-Bolognetti.

Cerboni, C., Ardolino, M., Santoni, A., and Zingoni, A. (2009). Detuning $\mathrm{CD}^{+} \mathrm{T}$ lymphocytes by downregulation of the activating receptor NKG2D: role of NKG2D ligands released by activated T cells. Blood 113, 2955-2964.

Chen, H. T., Bhandoola, A., Difilippantonio, M. J., Zhu, J., Brown, M. J., Tai, X., et al. (2000). Response to RAGmediated $\mathrm{V}(\mathrm{D}) \mathrm{J}$ cleavage by NBS1 and $\gamma$-H2AX. Science 290, 1962 1965.

Correa, I., Corral, L., and Raulet, D. H. (1994). Multiple natural killer cell-activating signals are inhibited by major histocompatibility complex class I expression in target cells. Eur. J. Immunol. 24, 1323 1331.

Eagle, R. A., and Trowsdale, J. (2007) Promiscuity and the single receptor: NKG2D. Nat. Rev. Immunol. 7, 737-744.

Eissmann, P., Evans, J. H., Mehrabi, M., Rose, E. L., Nedvetzki, S., and Davis, D. M. (2010). Multiple mechanisms downstream of TLR-4 stimulation allow expression of NKG2D ligands to facilitate macrophage/ $\mathrm{NK}$ cell crosstalk. J. Immunol. 184, 69016909.

Erickson, B. M., Thompson, N. L., and Hixson, D. C. (2006). Tightly regulated induction of the adhesion molecule necl-5/CD155 during rat liver regeneration and acute liver injury. Hepatology 43, 325-334.

Flodström-Tullberg, M., Bryceson, Y. T., Shi, F. D., Höglund, P., and Ljunggren, H. G. (2009). Natural killer cells in human autoimmunity. Curr. Opin. Immunol. 21, 634-640.

Fogli, M., Mavilio, D., Brunetta, E., Varchetta, S., Ata, K., Roby, G., et al. (2008). Lysis of endogenously infected CD4+ $\mathrm{T}$ cell blasts by rIL2 activated autologous natural killer cells from HIV-infected viremic individuals. PLoS Pathog. 4:7. doi: 10.1371/journal.ppat.1000101.

Fort, M. M., Leach, M. W., and Rennick, D. M. (1998). A role for NK cells as regulators of CD4+ T cells in a transfer model of colitis. J. Immunol. 161, 3256-3261.

French, A. R., and Yokoyama, W. M. (2004). Natural killer cells and autoimmunity. Arthritis Res. Ther. 6, 8-14. 
Fukao, T., Kaneko, H., Birrell, G., Tashita, H., Yoshida, T., Cross, S., et al. (1999). ATM is upregulated during the mitogenic response in peripheral blood mononuclear cells. Blood 94, 1998-2006.

Galazka, G., Jurewicz, A., Orlowski, W., Stasiolek, M., Brosnan, C. F., Rainem C. S., et al. (2007). EAE tolerance induction with Hsp70-peptide complexes depends on $\mathrm{H} 60$ and NKG2D activity. J. Immunol. 179, 4503-4512.

Gasser, S., Orsulic, S., Brown, E. J., and Raulet, D. H. (2005). The DNA damage pathway regulates innate immune system ligands for the NKG2D receptor. Nature 436, 1186-1190.

Groh, V., Bruhl, A., El-Gabalawy, H., Nelson, J. L., and Spies, T. (2003). Stimulation of $\mathrm{T}$ cell autoreactivity by anomalous expression of NKG2D and its MIC ligands in rheumatoid arthritis. Proc. Natl. Acad. Sci. U.S.A. 100, 9452-9457.

Hamerman, J. A., Ogasawara, K., and Lanier, L. L. (2004). Toll-like receptor signaling in macrophages induces ligands for the NKG2D receptor. J. Immunol. 172, 2001-2005.

He, J., Choe, S., Walker, R., Di Marzio, P., Morgan, D. O., and Landau, N. R. (1995). Human immunodeficiency virus type 1 viral protein $\mathrm{R}$ (Vpr) arrests cells in the G2 phase of the cell cycle by inhibiting $\mathrm{p} 34 \mathrm{cdc} 2$ activity. $J$. Virol. 69, 6705-6711.

Jinushi, M., Takehara, T., Kanto, T., Tatsumi, T., Groh, V., Spies, T., et al. (2003a). Critical role of MHC class I-related chain A and B expression on IFN-alpha-stimulated dendritic cells in NK cell activation: impairment in chronic hepatitis $\mathrm{C}$ virus infection. J. Immunol. 170, 1249-1256.

Jinushi, M., Takehara, T., Tatsumi, T., Kanto, T., Groh, V., Spies, T., et al. (2003b). Autocrine/paracrine IL-15 that is required for type I IFNmediated dendritic cell expression of MHC class I-related chain A and B is impaired in hepatitis $C$ virus infection. J. Immunol. 171, 5423-5429.

Jowett, J. B., Planelles, V., Poon, B., Shah, N. P., Chen, M. L., and Chen, I. S. (1995). The human immunodeficiency virus type 1 vpr gene arrests infected T cells in the G2 M phase of the cell cycle. J. Virol. 69, 6304-6313.

Kloss, M., Decker, P., Baltz, K. M., Baessler, T., Jung, G., Rammensee, H. G., et al. (2008). Interaction of monocytes with NK cells upon Toll-like receptor-induced expression of the NKG2D ligand MICA. J. Immunol. 181, 6711-6719.

Lang, P. A., Lang, K. S., Xu, H. C., Grusdat, M., Parish, I. A., Recher, M., et al. (2012). Natural killer cell activation enhances immune pathology and promotes chronic infection by limiting $\mathrm{CD}^{+}$T-cell immunity. Proc. Natl. Acad. Sci. U.S.A. 109, 1210-1215.

Lanier, L. L. (2008). Evolutionary struggles between NK cells and viruses. Nat. Rev. Immunol. 8, 259-268.

Leavenworth, J. W., Wang, X., Wenander, C. S., Spee, P., and Cantor H. (2011). Mobilization of natural killer cells inhibits development of collagen-induced arthritis. Proc. Natl. Acad. Sci. U.S.A. 108, 14584-14589.

Lee, I. F., Qin, H., Trudeau, J., Dutz, J., and Tan, R. (2004). Regulation of autoimmune diabetes by complete Freund's adjuvant is mediated by NK cells. J. Immunol. 172, 937-942.

Li, J., Rabinovich, B. A., Hurren, R., Cosman, D., and Miller, R. G. (2005). Survival versus neglect: redefining thymocyte subsets based on expression of NKG2D ligand(s) and MHC class I. Eur. J. Immunol. 35, 439-448.

Lu, L., Ikizawa, K., Hu, D., Werneck, M. B., Wucherpfennig, K. W., and Cantor, H. (2007). Regulation of activated $\mathrm{CD}^{+}{ }^{+} \mathrm{T}$ cells by $\mathrm{NK}$ cells via the Qa-1-NKG2A inhibitory pathway. Immunity 26, 593-604.

Lünemann, A., Lünemann, J. D., Roberts, S., Messmer, B., Barreira da Silva, R., Raine, C. S., et al. (2008). Human NK cells kill resting but not activated microglia via NKG2Dand NKp46-mediated recognition. J. Immunol. 181, 6170-6177.

Lünemann, A., Lünemann, J. D., and Münz, C. (2009). Regulatory NK-cell functions in inflammation and autoimmunity. Mol. Med. 15, 352-358.

Maasho, K., Opoku-Anane, J., Marusina, A. I., Coligan, J. E., and Borrego, F. (2005). NKG2D is a costimulatory receptor for human naive CD8 ${ }^{+} \mathrm{T}$ cells. J. Immunol. 174, 4480-4484.

Matloubian, M., Suresh, M., Glass, A., Galvan, M., Chow, K., Whitmire, J. K., et al. (1999). A role for perforin in downregulating T-cell responses during chronic viral infection. J. Virol. 73, 2527-2536.

Matsumoto, Y., Kohyama, K., Aikawa, Y., Shin, T., Kawazoe, Y., Suzuki, Y., et al. (1998). Role of natural killer cells and TCR gamma delta $\mathrm{T}$ cells in acute autoimmune encephalomyelitis. Eur. J. Immunol. 28, 1681-1688.

Matusali, G., Potestà, M., Santoni, A., Cerboni, C., and Doria, M. (2012). The human immunodeficiency virus type $1 \mathrm{Nef}$ and Vpu proteins downregulate the natural killer cell-activating ligand PVR. J. Virol. $86,4496-4504$.
Molinero, L. L., Fuertes, M. B., Rabinovich, G. A., Fainboim, L., and Zwirner, N. W. (2002). Activationinduced expression of MICA on T lymphocytes involves engagement of CD3 and CD28. J. Leukoc. Biol. 71, 791-797.

Molinero, L. L., Fuertes, M. B., Girart, M. V., Fainboim, L., Rabinovich, G. A., Costas, M. A., et al. (2004). NF $\kappa$ B regulates expression of the $\mathrm{MHC}$ class I-related chain A gene in activated T lymphocytes. J. Immunol. 173, 5583-5590.

Nedvetzki, S., Sowinski, S., Eagle, R. A., Harris, J., Vély, F., Pende, D., et al. (2007). Reciprocal regulation of human natural killer cells and macrophages associated with distinct immune synapses. Blood 109, 37763785.

Nielsen, N., Ødum, N., Ursø, B., Lanier, L. L., and Spee, P. (2012). Cytotoxicity of CD56 $6^{\text {bright }} \mathrm{NK}$ cells towards autologous activated $\mathrm{CD} 4{ }^{+} \mathrm{T}$ cells is mediated through NKG2D, LFA1 and TRAIL and dampened via CD94/NKG2A. PLoS ONE 7:e31959. doi: 10.1371/journal.pone.0031959

Nilsson, N., Bremell, T., Tarkowski, A., and Carlsten, H. (1999). Protective role of NK1.1+ cells in experimental Staphylococcus aureus arthritis. Clin. Exp. Immunol. 117, 63-69.

Nolte-'t Hoen, E. N. M., Almeida, C. R., Cohen, N. R., Nedvetzki, S., Yarwood, H., et al. (2007). Increased surveillance of cells in mitosis by human NK cells suggests a novel strategy for limiting tumor growth and viral replication. Blood 109 , 670-673.

Norman, J. M., Mashiba, M., McNamara, L. A., Onafuwa-Nuga, A., Chiari-Fort, E., Shen, W. etal. (2011). The antiviral factor APOBEC3G enhances the recognition of HIV-infected primary T cells by natural killer cells. Nat. Immunol. 12, 975-983.

Noval Rivas, M., Hazzan, M., Weatherly, K., Gaudray, F., Salmon, I., and Braun, M. Y. (2010). NK cell regulation of $\mathrm{CD} 4 \mathrm{~T}$ cell-mediated graft-versus-host disease. J. Immunol. 184, 6790-6798.

Nowbakht, P., Ionescu, M. C., Rohner, A., Kalberer, C. P., Rossy, E., Mori, L., et al. (2005). Ligands for natural killer cell-activating receptors are expressed upon the maturation of normal myelomonocytic cells but at low levels in acute myeloid leukemias. Blood 105, 3615-3622.

Ogasawara, K., Benjamin, J., Takaki, R., Phillips, J. H., and Lanier, L. L. (2005). Function of NKG2D in natural killer cell-mediated rejection of mouse bone marrow grafts. Nat. Immunol. 6, 938-945.

Olson, J. A., Zeiser, R., Beilhack, A., Goldman, J. J., and Negrin, R. S. (2009). Tissue-specific homing and expansion of donor NK cells in allogeneic bone marrow transplantation. J. Immunol. 183, 3219-3228.

Olson, J. A., Leveson-Gowere, D. B., Baker, J., Beilhack, A., and Negrin, R. S. (2010). NK cells mediate reduction of GVHD by inhibiting activated, aloreactive $\mathrm{T}$ cells while retaining GVT effects. Blood 115, 4293-4301.

Oricchio, E., Saladino, C., Iacovelli, S., Soddu, S., and Cundari, E. (2006). ATM is activated by default in mitosis, localizes at centrosomes and monitors mitotic spindle integrity. Cell Cycle 5, 88-92.

Pende, D., Castriconi, R., Romagnani, P., Spaggiari, G. M., Marcenaro, S., Dondero, A., et al. (2006). Expression of the DNAM-1 ligands, Nectin2 (CD112) and poliovirus receptor (CD155), on dendritic cells: relevance for natural killer-dendritic cell interaction. Blood 107, 2030-2036.

Pham, T. N., Richard, J., Gerard, F. C., Power, C., and Cohen, E. A. (2011). Modulation of NKG2Dmediated cytotoxic functions of natural killer cells by viral protein $\mathrm{R}$ from HIV-1 primary isolates. J. Virol. 85, 12254-12261.

Poggi, A., Prevosto, C., Massaro, A. M., Negrini, S., Urbani, S., Pierri, I., et al. (2005). Interaction between human NK cells and bone marrow stromal cells induces NK cell triggering: role of NKp30 and NKG2D receptors. J. Immunol. 175, 6352-6360.

Qiao, Y., Liu, B., and Li, Z. (2008). Activation of NK cells by extracellular heat shock protein 70 through induction of NKG2D ligands on dendritic cells. Cancer Immun. 8, 12-20.

Rabinovich, B. A., Li, J., Shannon, J., Hurren, R., Chalupny, J., Cosman, D., et al. (2003). Activated, but not resting, $\mathrm{T}$ cells can be recognized and killed by syngeneic NK cells. J. Immunol. 170, 3572-3576.

Re, F., Braaten, D., Frankem, E. K., and Luban, J. (1995). Human immunodeficiency virus type $1 \mathrm{Vpr}$ arrests the cell cycle in G2 by inhibiting the activation of p34cdc2-cyclin B. J. Virol. 69, 6859-6864.

Richard, J., Sindhu, S., Pham, T. N., Belzile, J. P., and Cohen, E. A. (2010). HIV-1 Vpr up-regulates expression of ligands for the activating NKG2D receptor and promotes NK cell-mediated killing. Blood 115, 1354-1363.

Roshal, M., Kim, B., Zhu, Y., Nghiem, P., and Planelles, V. (2003). Activation 
of the ATR-mediated DNA damage response by the HIV-1 viral protein R. J. Biol. Chem. 278, 25879-25886.

Rossini, G., Cerboni, C., Santoni, A., Landini, M. P., Landolfo, S., Gatti, D., et al. (2012). Interplay between human cytomegalovirus and intrinsic/innate host responses: a complex bidirectional relationship. Mediat. Inflamm. 2012, 1-16.

Roy, S., Barnes, P. F., Garg, A., Wu, S., Cosman, D., and Vankayalapati, R. (2008). NK cells lyse T regulatory cells that expand in response to an intracellular pathogen. J. Immunol. 180, 1729-1736.

Ruggeri, L., Capanni, M., Urbani, E., Perruccio, K., Shlomchik, W. D., Tosti, A., et al. (2002). Effectiveness of donor natural killer cell alloreactivity in mismatched hematopoietic transplants. Science 295, 2097-2100.

Schott, E., Bonasio, R., and Ploegh, H. L. (2003). Elimination of in vivo developing T cells by natural killer cells. $J$. Exp. Med. 198, 1213-1224.

Schrama, D., Terheyden, P., Otto, K., Kämmerer, U., Bröcker, E. B., Lühder, F., et al. (2006). Expression of the NKG2D ligand UL16 binding protein-1 (ULBP-1) on dendritic cells. Eur. J. Immunol. 36, 65-72.

Schulz, U., Kreutz, M., Multhoff, G., Stoelcker, B., Köhler, M., Andreesen, R., et al. (2010). Interleukin-10 promotes NK cell killing of autologous macrophages by stimulating expression of NKG2D ligands. Scand. J. Immunol. 72, 319-331.

Shi, F. D., Takeda, K., Akira, S., Sarvetnick, N., and Ljunggren, H. G. (2000). IL-18 directs autoreactive T cells and promotes autodestruction in the central nervous system via induction of IFN-gamma by NK cells. J. Immunol. 165, 3099-3104.

Shi, F. D., and Van Kaer, L. (2006). Reciprocal regulation between natural killer cells and autoreactive T cells. Nat. Rev. Immunol. 6, 751-760.

Shibuya, A., Campbell, D., Hannum, C., Yssel, H., Franz-Bacon, K., McClanahan, T., et al. (1996). DNAM-1, a novel adhesion molecule involved in the cytolytic function of $\mathrm{T}$ lymphocytes. Immunity 4, 573-581.
Sivori, S., Carlomagno, S., Falco, M., Romeo, E., Moretta, L., and Moretta, A. (2011). Natural killer cells expressing the KIR2DS1-activating receptor efficiently kill T-cell blasts and dendritic cells: implications in haploidentical HSCT. Blood 117, 42844292.

Skov, S., Pedersen, M. T., Andresen, L., Straten, P. T., Woetmann, A. and Odum, N. (2005). Cancer cells become susceptible to natural killer cell killing after exposure to histone deacetylase inhibitors due to glycogen synthase kinase-3-dependent expression of MHC class I-related chain A and B. Cancer Res. 65, 1113611145 .

Smeltz, R. B., Wauben, M. H., Wolf, N. A., and Swanborg, R. H. (1999). Critical requirement for aspartic acid at position 82 of myelin basic protein 73-86 for recruitment of $\mathrm{V}$ beta $8.2+$ $\mathrm{T}$ cells and encephalitogenicity in the Lewis rat. J. Immunol. 162, 829-836.

Spaggiari, G. M., Capobianco, A., Becchetti, S., Mingari, M. C., and Moretta, L. (2006). Mesenchymal stem cell-natural killer cell interactions: evidence that activated NK cells are capable of killing MSCs, whereas MSCs can inhibit IL-2-induced NKcell proliferation. Blood 107, 14841490.

Soriani, A., Zingoni, A., Cerboni, C., Iannitto, M. L., Ricciardi, M. R., Di Gialleonardo, V., et al. (2009). ATM-ATR dependent up-regulation of DNAM-1 and NKG2D ligands on multiple myeloma cells by therapeutic agents results in enhanced NK-cell susceptibility and is associated with a senescent phenotype. Blood 113, 3503-3511.

Stanietsky, N., Simic, H., Arapovic, J., Toporik, A., Levy, O., Novik, A., et al. (2009). The interaction of TIGIT with PVR and PVRL2 inhibits human NK cell cytotoxicity. Proc. Natl. Acad. Sci. U.S.A. 106, 17858-17863.

Su, H. C., Nguyen, K. B., SalazarMather, T. P., Ruzek, M. C., Dalod, M. Y., and Biron, C. A. (2001). NK cell functions restrain $\mathrm{T}$ cell responses during viral infections. Eur. J. Immunol. 31, 3048-3055.
Tahara-Hanaoka, S., Shibuya, K., Onoda, Y., Zhang, H., Yamazaki, S., Miyamoto, A., et al. (2004). Functional characterization of DNAM1 (CD226) interaction with its ligands PVR (CD155) and nectin-2 (PRR-2/CD112). Int. Immunol. 16, 533-538.

Tahara-Hanaoka, S., Shibuya, K., Kai, H., Miyamoto, A., Morikawa, Y. Ohkochi, N., et al. (2006). Tumor rejection by the poliovirus receptor family ligands of the DNAM-1 (CD226) receptor. Blood 107, 14911496.

Tanaka, T., Kajstura, M., Halicka, H. D., Traganos, F., and Darzynkiewicz, Z. (2007). Constitutive histone H2AX phosphorylation and ATM activation are strongly amplified during mitogenic stimulation of lymphocytes. Cell Prolif. 40, 1-13.

Van Belle, T. L., and von Herrath, M. G. (2009). The role of the activating receptor NKG2D in autoimmunity. Mol. Immunol. 47, 8-11.

Venkataraman, G. M., Suciu, D., Groh, V., Boss, J. M., and Spies, T. (2007). Promoter region architecture and transcriptional regulation of the genes for the MHC class I-related chain A and B ligands of NKG2D. J. Immunol. 178, 961-969.

Waggoner, S. N., Cornberg, M., Selin, L. K., and Welsh, R. M. (2011). Natural killer cells act as rheostats modulating antiviral T cells. Nature 481, 394-398.

Ward, J., Bonaparte, M., Sacks, J., Guterman, J., Fogli, M., Mavilio, D., et al. (2007). HIV modulates the expression of ligands important in triggering natural killer cell cytotoxic responses on infected primary T-cell blasts. Blood 110, 12071214.

Ward, J., Davis, Z., DeHart, J., Zimmerman, E., Bosque, A., Brunetta E., etal. (2009). HIV-1 Vpr triggers natural killer cell-mediated lysis of infected cells through activation of the ATR-mediated DNA damage response. PLoS Pathog. 5:10. doi: 10.1371/journal.ppat.1000613

Xu, W., Fazekas, G., Hara, H., and Tabira, T. (2005). Mechanism of natural killer (NK) cell regulatory role in experimental autoimmune encephalomyelitis. J. Neuroimmunol. 163, 24-30.

Yamaji, O., Nagaishi, T., Totsuka, T., Onizawa, M., Suzuki, M., Tsuge, N., et al. (2012). The development of colitogenic CD4(+) T cells is regulated by IL-7 in collaboration with $\mathrm{NK}$ cell function in a murine model of colitis. J. Immunol. 188, 25242536.

Yang, C., and Kastan, M. (2000). Participation of ATM in insulin signalling through phosphorylation of eIF-4Ebinding protein 1. Nat. Cell Biol. 2, 893-898.

Zhang, B., Yamamura, T., Kondo, T., Fujiwara, M., and Tabira, T. (1997). Regulation of experimental autoimmune encephalomyelitis by natural killer (NK) cells. J. Exp. Med. 186, 1677-1687.

Conflict of Interest Statement: The authors declare that the research was conducted in the absence of any commercial or financial relationships that could be construed as a potential conflict of interest.

Received: 30 October 2012; paper pending published: 21 November 2012; accepted: 17 December 2012; published online: 09 January 2013.

Citation: Zingoni A, Ardolino M, Santoni $A$ and Cerboni $C$ (2013) NKG2D and DNAM-1 activating receptors and their ligands in NK-T cell interactions: role in the NK cell-mediated negative regulation of $T$ cell responses. Front. Immun. 3:408. doi: 10.3389/fimmu.2012.00408

This article was submitted to Frontiers in NK Cell Biology, a specialty of Frontiers in Immunology.

Copyright (c) 2013 Zingoni, Ardolino, Santoni and Cerboni. This is an openaccess article distributed under the terms of the Creative Commons Attribution License, which permits use, distribution and reproduction in other forums, provided the original authors and source are credited and subject to any copyright notices concerning any third-party graphics etc. 